\title{
Dentist required to join expedition to Mongolia
}

A self-funded dentist is required to join the Mongolian Khan Khentil Expedition to be led by Colonel John Blashford-Snell in late June 2020.

East of Ulaanbaatar, the Hentii mountain range rises out of a vast protected area of 1.2 million hectares covering the transition zone between the taiga and mountain forest steppe. The cedar and larch forests only grow on the Northern slopes, whilst on the Southern side of the mountains there are grasslands. Much of this remote wilderness is uninhabited and accessible only on foot or horse (it would be an advantage but not essential to be an experienced horse rider).

Over 1,000 plant species and 50 mammals, including endangered moose, musk deer, brown bear, wolf, lynx, badger, fox, wolverine, marmot, weasel, sable, roe deer and maral can be found here. Bird lovers will be able to see up to 250 types of birds, including hooper swans, spoonbills, egrets and raptors.

The rich heritage of human settlement in Hentii is marked with numerous rock carvings of the Upper Palaeolithic and Stone Age period, deer stones (or stelae) and Bronze age tombs. There is also the mysterious Great Wall of Chinggis Khaan, or Ghenghis Khan as he is often referred to currently. It is firmly believed by the Mongolian people that the legendary leader and warrior was born in the Hentii and is buried in the area.

The expedition will be carrying out community aid projects, giving dental and medical help to the local people and performing archaeological, biological and zoological tasks with Mongolian scientists. The scientific studies are organised with the support of the National University.

\section{BOOK REVIEW}

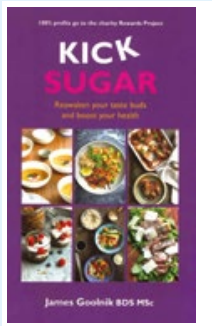

\author{
KICK SUGAR \\ James Goolnik; \\ 2020; Bow Lane Limited; \\ f20; pp. 192; \\ ISBN 978-1-5272-4941-7
}

Kick sugar, the passion project of dentist James Goolnik, is part interactive information book, part recipe book. It explores our complex relationship with sugar and aims to challenge modern attitudes to diet. The book is intended for patients, parents, and anyone who is interested in improving health and lifestyle by reducing the amount of sugar in their diet - culminating in a 14-day sugar challenge with meal-by-meal recipes for each day.

It is well known that sugar is bad for your teeth, and although written by a dentist there is only a relatively small chapter on sugar and dental health. The book mainly focuses on the holistic impact of our sugar dependence, from mental health to diabetes. The author co-writes with nutritional therapist Jenny Philips, giving clear evidence for links between sugar and obesity, depression, skin problems, low energy, and much more.

Once we have been convinced by the science, the book progresses from theory to provide a more practical approach to reducing our sugar intake. Where are manufacturers hiding sugar?

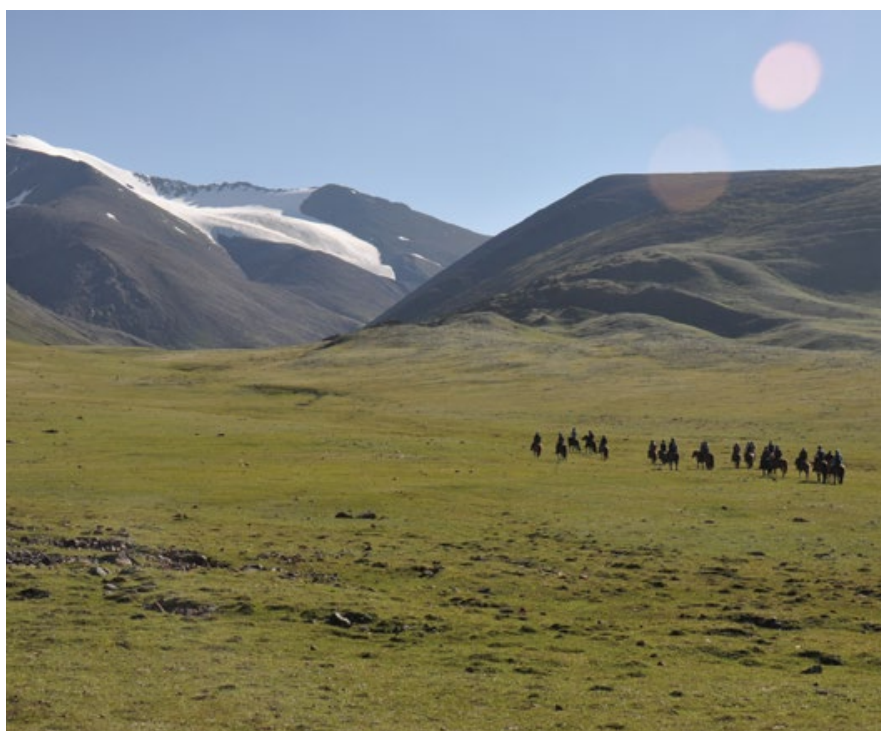

Travel will be by horse and four-wheel drive vehicles. Accommodation will be in tents provided by local agents. At the end of the expedition there will be two days in the Khustain Nuruu National Park (West of Ulaanbaatar) studying the Przewalski horses and carrying out zoological research.

The provisional dates are 28 June -7 July (arriving and departing Ulaanbaatar). If you would like further information, email jbs@sesexplore.org or telephone 01747854456.

Why is our intake so high? What can the reader do?

The following section of the book answers these questions, focusing on the 14-day sugar challenge. Goolnik teams up with professional chefs Giancarlo and Katie Caldesi (who share that their own drive for cutting sugar was after Giancarlo was diagnosed as Type 2 diabetic) to provide a step-by-step recipe book suitable for even the most novice chef. The 14-day-sugar challenge is a comprehensive two-week diet programme to follow, providing 14 recipes for breakfast, lunch, and dinner (and yes, even the occasional dessert).

Overall, Kick Sugar provides easy to read information that would appeal to busy readers; colourful charts highlight important information and beautiful imagery entices the reader to try the sugar reducing recipes. 'False Beliefs' sections challenge popular opinion, and 'Top Tips' sections summarise the chapters, providing useful and practical information for the reader. Although the book provides scientific background, the text is not overly difficult to follow, and holds the reader's attention with bold interesting facts.

Kick Sugar complements what we preach to our patients. It could be a useful tool to signpost our patients and parents to in order to get more information if they are truly looking to overhaul their diet. If that is not reason enough to try this book, $100 \%$ of the profits go to the author's charity Rewards Project, which provides resources to tackle the sugar epidemic by changing reward systems in our homes, schools, and workplaces.

Zara Leighton 